\title{
Antep'te Ermeni Ulusçuluğunun Doğuşunda Amerikalılar ve Kolejin Etkisi
}

\author{
Doç. Dr. Bülent ÇUKUROVA*
}

\section{ÖZET}

Bu çalışmanın amacı, 19. yy'ın ikinci yarısında Ermeni etnik gruplarını eğitip, birlik olmalarını ve ulusal ayaklanmalarını sekillendirmek amacıyla ABCFM tarafından Antep'te açılan okulların rollerini ve Ermenilerle Müslüman Türkler arasındaki ilişkileri incelemektir. Bu amaçla, okulların açıldığı sosyo-tarihsel koşullar, öğrenciler, ĕ̆itim programları, yönetim yapısı ve mali kaynakları ile ilgili toplanan veriler analiz edilmiştir ${ }^{I}$.

\section{ABSTRACT}

This study aims at examining the role of schools opened by the ABCFM in order to educate Armenian ethnic groups in the second half of the 19th.century and to shape their completeness and national uprising and the relationship between Armenians and Muslim Turks. For this purpose, the collected data for the sociohistorical conditions in which these schools opened, the student population, the curriculum, the administrative structure and the financial sources were analysed ${ }^{l}$.

Ermenilerin ulusal kimlik bilinci edinmelerinde, Müslüman toplum ile Hıristiyan Ermeni toplumu içinde sosyo-ekonomik farklılıkların giderek artmasına, Ermenilerde etnik kimlik bilincinin ortaya çıkmasına iki temel olgu yol açmış görünmektedir. Birincisi XIX. Yüzyıl ortalarından itibaren Antep'te açılan American Board of Commissioners for Foreign Missions'a $(A B C F M)$ ait okullar ki Amerikalıların eğitim faaliyetlerinin yoğunlaşmasıyla, Ermeni örgütlerinin kışkırtıcı ve teröre dönük faaliyetleri

\footnotetext{
* Çukurova Üniversitesi, Eğitim Fakültesi.
}

${ }^{1}$ Bu çalışma ODTÜ Sosyal Bilimler Derneği tarafından yapılan 9. Sosyal Bilimler Derneği Kongresi’nde (7-9.12.2005) sunulan tebliğ genişletilerek hazırlanmıştır. 
paralellik göstermektedir, ikincisi ise batılı devletler desteğinde Anadolu'daki azınlıklara verilen siyasi ve sosyal ayrıcalıklarla, Osmanlı toplumu içindeki farklı dinlere mensup toplulukların, yerel iktidarlardan bağımsız hareket ederek sosyal ve ekonomik olarak kendilerini geliştirip, Müslümanlardan farklılaşmalarıdır. Batılı kaynaklar da bu çerçevede, Amerikalı Protestan misyonerlerin, açtıkları okulları ihtilal merkezleri haline getirdiklerini, uygulanan programların Ermenilerde özgürlük ve bağımsızlık düşüncesini uyandırdığı, onların etnik kimlik bilinci edinmelerini sağladığını ileri sürmektedir².

Başta ABD olmak üzere dönemin batılı büyük devletleri Osmanlı imparatorluğu'ndaki gayri müslim azınlıklara özel bir ilgi göstermişlerdir. Millet sistemine dayalı Osmanlının merkeziyetçilikten uzak yönetim anlayışı azınlıkların dini, kültürel, eğitsel faaliyetlerini kendi imkanlarıyla ve de özgürce yerine getirmesine imkan tanıyan yapısı da bu süreçte etkili olmuştur. Batılı devletlerin gösterdiği bu yakın ilginin ekonomik, sosyal, siyasi çok farklı boyutlar mevcuttur. Misyonerlik faaliyetleri temelinde örgütlenen bu ilgi, esas itibariyle dağılmakta olan Osmanlı İmparatorluğu'nun sınırları dahilindeki enerji-petrol kaynaklarını kontrol etmek, sınırları yeniden çizilmekte olan bölge üzerinde süregiden uluslararası rekabette global güç dengelerini lehine çevirmek amacına matuftur. Bölgedeki gayri müslim azınlıklara yönelik eğitim faaliyetleri bu süreçte özel bir yer tutar.

Osmanlı İmparatorluğu'nda yabancı okulların sayısı değişik kaynaklarda 800-7000 arasında gösterilse de, bu sayı gerçekte 850-900 arasındadır. Yabancı okullar içinde Amerikan misyoner okulu sayısı 161'dir. Bunların 130 tanesi Lübnan, Kudüs, Suriye, Halep, Adana, Sivas, Elazığ, Diyarbakır, Erzurum, Van bölgelerinde açılmıştır ${ }^{3}$

ABCFM 1810'da Boston'da kurulmuş, 1820 yılında Anadolu'ya ilk Amerikalı misyonerler gelmeye başlamıştır. Antep'e ilk gelen misyoner Dr.Thomas P. Johnson'dır. Halk içinde kendisine gösterilen tepki nedeniyle ABCFM tarafından geri alınmak zorunda kalınmış, yerine Dr. Azariah Smith gönderilmiştir ${ }^{4}$. Smith'ten sonra 1851-1869'da Dr. Andrew T.Pratt, 1874 sonrası David H. Nutting doktorluk yanında vaizlik ve örgütleme çalışmalarını sürdürmüş, bu çalışmalar, Antep'te "kuvvetli bir Protestan topluluğu"nun ortaya çıkmasına yol açmıştır 5 .

${ }^{2}$ Kocabaş, Süleyman, Türkiye'de Gizli Tarih III, Misyonerlik ve Misyonerler, Vatan Yay., İstanbul 2002. s.156-159.

${ }^{3}$ Mutlu, Samil, Osmanl Devleti'nde Misyoner Okulları, Gökkubbe Yay., İstanbul 2005. s.326, 375 .

${ }^{4}$ American Board of Commissioners for Foreign Missions, A Century of Service in the Fountain of Healing, HAK. PAMPH. Folio RA, 99 B, T8, Z 11.

${ }^{5}$ Bilezikian, V. S., Abraham Hoja of Aintab, Light and Life Press, Winona Lake, Indiana. S. 127 
1874 yılında eğitime başlayan Merkezi Amerikan Koleji'nin Tıp departmanı 1876 'da hizmete girmiştir. Okul mütevelli heyeti Amerika'da bulunan 9 üyeden oluşurken, altta idare heyetindeki 13 kişi Osmanlı topraklarında yaşayan misyonerler ve Ermenilerdi ${ }^{6}$. Avrupa'da bu dönemde ilkokul 6 , ortaöğretim 7 yıl, daha sonra üniversite eğitimi verilirken, kolej Amerikan eğitim sistemine göre organize olmuştu. Yaygın eğitim 8, yüksekokul (lise) 4 yıl, kolej 4 y1l idi. Okulda çalışan idari personel ve öğretmen kadrosu da Ermenilerden oluşturulmuştu. Okulda eğitim gören öğrenciler Antep, Maraş, Urfa, Gürün, Haçin, Kilis, Diyarbakır, Sivas, Siverek, Hatay, Harput, Arapkir, Çermik, Adana'dan toplanmış Ermeni çocuklardı ${ }^{7} .1876$ 'da kazada Müslümanlara ait bir rüștiye (ortaokul) varken ikincisi 1908 'de açıldı. İdadi (lise) ise 1911 'de eğitime girdi' ${ }^{8} .1854$ 'de gayrimüslimlerin eğitildiği 3 ortaokul varken, 1900 'de bu sayı 11 e çıkmıştır'. Müslüman öğrenciler ise Antep'teki Darü'l-Harir (ipekçilik okulu) dışında yalnızca Halep Sultanisi'ne gidebiliyordu ${ }^{10}$. Ermeni çocukların okul sonrası kendi yörelerine giderek faaliyet gösterecekleri düşünülürse, Amerikalıların etki altına almak istedikleri bölge de açıkça görülür.

1868 'de Antep'te 10.802 Müslüman, 4933 Hıristiyan, 274 Musevi yaşamaktadır. 1883 'de şehir nüfusu 31.486 , bunun yaklaşık $2 / 3$ si Müslümandır. II. Meşrutiyet dönemine gelindiğinde daha detaylı bir sınıflandırmayla, kazada 69.842 Müslüman, 13.937 Gregorien Ermeni, 4577 Protestan, 675 Musevi, 470 katolik Ermeni, 54 Ortodoks, 9 Süryani yaşadığı görülür ${ }^{11}$.

Öğrencilerin yaklaşık 2/3 si Protestan, diğerleri Gregoriendi. 1914 öncesinde okulda yalnızca 3 Müslüman öğrenci bulunuyordu ${ }^{12}$. Bu da doğaldı çünkü kolej yerli Ermenilerin de çalışmaları ve paralarıyla kurulmuştu. Müslümanlar yerel güçlerle de bir şeyler yapılabileceğinin geç farkına varmışlardı. Örneğin Ermeni yetimhaneleri Amerikan-İngiliz vakıfları ve yerli Ermenilerin işbirliği ile kurulup, işletilirken, Antep

${ }^{6}$ Ayıntab'da Kain Merkezi Türkiye Koleji'nin 39. Senevi Raporu, Kolej Matb., Ayıntab 1332. s.3-4

Catalogue of Central Turkey College at Aintab 1880, Vilaye of Aleppo, 1881, Matteosian, Constantinople 1991, s.31-35. s.85.

${ }^{8}$ Solmaz, M. - Yetkin H., Gaziantep Çevre Incelemesi, Yeni Matbaa, Gaziantep 1969. (1992) s.5-6.

${ }_{10}$ Y.5-6. Hizmetleri. Gaziantep Vilayet Merkezinin 76 Sene Evveline Kadar Olan Mahalli Maarif Hareketlerinin Kısa Bir Tarihçesi, Gaziyurt Matb., Gaziantep 1955. s.52-53.

${ }^{11}$ Salname-i Vilayet-i Haleb, Haleb Vilayeti Matbaasi, Haleb, 1285, 1326.

${ }^{12}$ Report of the President of Central Turkey College, Aintab, The Board of Manager of the College, 1913-1914. PUMPH Folio RA, 990, T8, Z 91. s. 3-4, 10, 28. 
zenginleri ilk Müslüman çocuklara ait yetimhaneyi XX. yüzyıl başında yapabildiler ${ }^{13}$.

1870'lerden sonra $A B C F M$ ve kiliseler kız çocukların da eğitimine önem vermeye başladılar. Bu okulların öğretmenleri de kadınlardan seçildi. Mrs.Schneider, Myra Practor, Ellen M. Pierce, Lucille Foreman, Mrs.Merill, Blake, Mrs.Norton Amerikalı ögretmenlerden bazılarıydı ${ }^{14}$. Bu okul 1907'den 1912'ye kadar gelişme gösterdi ve ögrenci sayısı bu sürede ikiye katland ${ }^{15}$.

Antep'te XIX. yüzyılda 18 medrese bulunuyordu. Vakıflar tarafından yürütülen bu kurumlarda din ağırlıklı eğitim yapılmaktaydı ${ }^{16}$. Buna karşın, kolejde açıldığı yıllarda İngilizce, modern Ermenice, eski Ermenice, Türkçe, matematik, cebir, geometri, trigonometri ve ölçüm, doğa felsefesi, astronomi, coğrafya, psikoloji, Ermeni, Türk ve Dünya Tarihi okutulurken ${ }^{17}$, Birinci Dünya Savaşı öncesinde dersler din bilimleri (3), doğa bilimleri (5), matematik bilimleri (2), hayat bilgisi (1), insan bilimleri (1), genel tarih ve Osmanlı tarihi (2), felsefe (1), hukuk bilgileri, ticaret ve ekonomi bilgileri, eğitim bilimleri (1), madencilik (1), Osmanlı dil ve edebiyatı (4), Ermenice (2), Arapça (1), İngilizce (3), Almanca (1), Fransızca (2), Yunanca (1 seçmeli), güzel yazı (2), resim (1), beden (2) şeklinde değişmiştir (39. Senevi Rapor 1914. s.6). Bu derslerden farklı olarak 1914-1915 eģitim döneminde İbranice de okutulmuştur. Ermenice derslerinde Türkçe konuşmak kesinlikle yasaklanmıştır ${ }^{18}$. Çağdaş tarih dersleri Türk tarihi ile ilişkilendirilerek karşılaştırmalı anlatılırken, Osmanlı tarihi içinde Ermeni tarihi de verilmiştir ${ }^{19}$.

1915 Eylülünden itibaren İttihat-Terakki tarafından getirilen yeni Maarif Nizamnamesi uyarınca Vilayet Maarif Müdüriyeti, diğer dillere verilen önem kadar Türkçe dil ve edebiyatına zaman ayrılması, Osmanlı tarih ve coğrafyasının Türkçe ve Türkçe ders kitaplarından okutulmasını Kolej yönetiminden istemiştir. Buna karşın yönetim Ermenice ders saatlerini artırmıs, 1914-1915 eğitim yılında ilk kez detaylı Ermeni edebiyatı okutulmuş, üst sınıflarda başka dillerden Ermeniceye çeviri dersleri verilmiştir. Yine hükümet politikaları uyarınca kolej arazi ve binaları 1914'e kadar vergiden muaf iken, 1914'te vergiye tabi tutulunca Amerikan sefareti

${ }^{13}$ Yener, A.g.e., s.37-38

${ }^{14}$ Boston Massachusette'de bulunan Woman's Board of Missions'a yazılan rapor.Blake, Isabel M., Looking Backward Fifty Years in Aintab, Turkey. s. 3.

${ }^{15}$ Blake, A.g.e., s. 4.

${ }^{16}$ Yener, A.g.e., s.6-7.

${ }^{17}$ Catalogue of CTC, s.9.

${ }^{18}$ Report of the President, s.6-7, 16.

${ }^{19}$ Report of the President, s.17; 39.Senevi rapor, s21. 
devreye girmiş, aradaki görüşmeler sonucu koyulan vergiler tehir edilmiştir ${ }^{20}$.

Politik etkinlikler okulda önem verilen bir konu olmuştur. 1913-1914 eğitim yılı başında öğretmenler politik konularda öğrencilerin sorularını yanıtlayıp, politik sorumlulukları anlatan konuşmalar yapmışırı. Zaman zaman kolej kütüphanesinden yasaklı kitapların ayıklanabilmesi amacıyla komiteler kurulmuştur. Merkezi Türkiye Koleji'nde bulunan kitapların $\% 11.3$ ü Arapça, Türkçe, \%17.6 sı Ermenice, \%71 İngilizce ve Fransızcadır. 1908 'den 1914'e kadar okunan kitap sayısında dönemin siyasi gelişmelerine paralel olarak düzenli ve periyodik bir artış bulunmaktadır, 1908'lerde okunan kitap sayısı 3349 iken $^{21}$, 1914'lerde bu ${ }^{22} 10942$ ye çıkmıştır ${ }^{23}$. Kolejde Ermenice kitapların okunma oranı Türkçe ve İngilizce kitaplardan fazla olmuştur ${ }^{24}$. Savaş başlarında İngilizce kitapların okunuş oranında artış olmuştur $^{25}$.

Kolejin son sınıf tezlerinde (4.) yerel etnik ve dinsel kültürü araştıran, Ermeni kültürünü içeren tezlerin hazırlatılmasının ayrı bir önem taşıdığ gözlenmektedir. Örnek olarak, Urfa'da dinsel kültür, Urfa'da çocuk işçiler, Urfa çeyizleri, Harran ve yerlileri, Antep'te taş inşası ve endüstrisi, Türkiye'de hapishaneler, Türklerin sosyal yaşamı, Çerkezler, Türkiye'de batıl inançlar, Urfa'daki Ermenilerin lehçeleri ve gelenekleri, Ermenilerin entelektüel gelişiminde felsefenin yeri, Ermenice müzik ve ilahi, Akdamar manastırı, Ermeni Protestanlığının tarihi ve geleceği, Ermeni politik dernekleri, Ermenilerin ticari tarihi verilebilir ${ }^{26}$.

Birinci Dünya Savaşı'nın başlaması öğrenci ve öğretmenler açısından sıkıntı yaratmıştır. Savaş öncesi okul ortalama \%6 civarında mezun verirken $^{27} 1914$ 'te mezun verilmemiştir. Savaş öncesi ögrenciler giderek artan oranlarda askeri yükümlülükler nedeniyle okuldan ayrılmışırır ${ }^{28}$. Aynı durum öğretmenler için de geçerlidir. Askere alınacak öğretmenlerin okuldan ayrılmamasını sağlamak için kolej idare heyeti gereksinimi olan ögretmenlere borç vererek, bedel-i nakdilerini ödeyip gidişlerini önleme çabası içine girmiştir ${ }^{29}$.

Gelirleri $A B C F M$ 'un yüksek ögretim fonu ile yerel Ermeni halkın bağışlarından sağlanan Kolejin Antep çevresindeki Amerikan okullarına da

\footnotetext{
${ }^{20}$ 39. Senevi Rapor, s.16-18.

${ }^{21}$ ögrenci sayısı 201

22 öğrenci sayısı 232.

${ }^{23}$ Report of the President, s.12-14.

${ }^{24} 1912-1913$ te Türkçe-Ermenice-İngilizce oran 3-5-2 iken, 1914'te 3-4-3 tür.

${ }^{25}$ 39. Senevi Rapor, s.14.

${ }^{26}$ Report of the President, s.9-10, 16, 19.

${ }_{27} 1911$ - \%7.26, 1912-\%4.91; 1913-\%7.80.

${ }^{28}$ Report of the President, s.10.

${ }^{29}$ 39. Senevi rapor, s.4-5.
} 
eğitsel ve parasal açıdan destek olduğu görülmektedir. Urfa, Keşab, L un, Birecik, Kilis okullarına az da olsa para yardımı yapılmış, Urfa ve Kilis okullarıyla eğitim hususunda bir mukavele imzalanmışıิı ${ }^{30}$. Örneğin Kayseri kilisesine gönderilen kolej mezunlarından Tahmisian ve Aijian faaliyetlerini mezralara kadar yaymıs, burada "Pathfinder" isimli bir dergi çıkarmışlardır ${ }^{31}$.

1867'ye kadar Antep'teki 3 kiliseden biri protestanlara aittir, bu tarihte Protestanlar iki kilise daha açmıştır. Protestan nüfusun hızla artmasının nedeni, doğum ve ölüm işlemlerini kendileri yapmaları ile vergi muafiyetidir. Bunun karşılığında diğer Ermeni ve Rum kiliselerine gitmemeleri istenmiştir kendilerinden ${ }^{32}$. 1893 'te 13.940 hıristiyandan 2319'u (\%16) Protestan iken, 1908'de 18.984 Hıristiyandan 4577'si (\%24) protestandir ${ }^{33}$.

1860'lardan sonra misyonerler tarafından Gregorien topluma organize bir eğitim verildiği gözlenmektedir. 1907'lere kadar okul sayılarında düzenli bir artış vardır (Musevi topluluğun eğitimi de Hıristiyan okullarında verilmiştir). İlkokulların yaklaşık \% 61 'inde Protestanlar tarafından eğitim etkinlikleri sürdürülmüștür. Hıristiyan toplum içinde eğitim alanların oranı ise \% 10'lardadır ${ }^{34} .1907$ yılında Antep'teki Amerikan okulları da tüm Anadolu'dakilere yapıldığı gibi araştırmaya tabi tutulmuştur. Bu sırada şehirde Merkezi Amerikan Koleji dışında bir kız okulu, 3 ilkokul, bir yetimhane, hastane ve meskenler bulunmaktadır ${ }^{35}$.

1890'lardan itibaren Amerikan okullarının olduğu bölgelerde çıkan Ermeni hareketlerinde Amerikan okullarının da etkili olduğu saptanmış bazı kolej öğretmenleri yargılanmıştır ${ }^{36}$. Zaten Merkezi Türkiye Koleji Yönetim Kurulu'nun aldığı bir karar da Ermeni toplumunun nasıl bir psikoloji içinde olduğunu vurgular gibidir. 1914'te okul eylem planı içinde öğrencilerde silah bulunduğu takdirde, bulara el koyulması kararlaştırılmıştır. Bu durum Ermeni topluluğun bir kısmının silah taşıdığı ve hatta bazı öğrencilerin silahla okula gelebildiğini göstermektedir ${ }^{37^{3}}$. Bu olayların Antep'teki uzantısı "Balta Savaşı" adıyla yaşanmıştır. Ermeni saldırganların elebaşıları Halep'e

${ }^{30}$ Report of the President 1914, s.9, 25.

${ }^{31}$ Bilezikian, A.g.e., s.110.

Güzelbey, Cemil Cahit, Gaziantep Seri Mahkeme Sicilleri, c.142, Gaziantep Kült.Der.Yay., Gaziantep 1966. s. 74; c.45, s.37.

${ }^{33}$ Salname-i Vilayet-i Haleb, 1310, s.194; 1326, s.243.

${ }^{34}$ Salname-i Nezaret-i Maarif-i Umumiye, Matbaa-i Amire, İstanbul 1317, s.11261127.

${ }^{35}$ Mutlu, A.g.e., s.329.

${ }^{35}$ Mutlu, A.g.e., s. 309-310.

${ }^{37}$ Report of the President, s.8. 
sürülmüş, Abdülhamit'e yapılan başvurular üzerine serbest bırakılmışlardır ${ }^{38}$. Bu olaylar üzerine Ermeni mahallelerinin çevresine dört karakol yapma zorunluluğu doğmuştur.

II. Meşrutiyet yıllarında Hınçak Fırkası Antepli Ermeniler üzerinde etkisini artırmıştır. Mart 1909 Adana olaylarından sonra mahalleleri değişik bölümlere ayıran Ermeniler sokakların başına silahlı gruplar yerleștirmiş, Gazarian köşkünü merkez edinmiştir ${ }^{39}$. Türklerin yapılanlara tepki göstermemesi olay çıkmasını engellemiştir.

Birinci Dünya Savaşı'nda Ermenilerin çoğu bedel ödeyerek askere gitmemiş, yalnızca doktorlar askere alınmıştır. Ermeniler daha önceki faaliyetleri nedeniyle silahsızlandırılmış, bazı gençler özel çalışma gruplarında çalıştırılmıştır. Savaş sırasında bazı Ermeni liderleri ve tahrikçiler, yaklaşık 1200 kişi Hama, Humus ve Şam civarında zorunlu ikamete tabi tutuldular. Bunun önlenmesi için Kolejde de görev yapan Dr. Shepard padişah nezdinde çabalarda bulundu ${ }^{40}$. İkamete tabi tutulan Ermenilerin tamamı mütareke sonrası yerlerine döndüler.

15.1.1919'da kaza İngilizlerce işgal edilirken, Ermeniler büyük bir coşku ve sevinç gösterileriyle karşıladılar işgalcileri ${ }^{41}$. Daha sonraki asıl olayların çıkacağı, Ermeni lejyonunun halka büyük baskılar yapacağı Fransız işgalinde ise işgal kuvvetlerinin karargahı Merkezi Amerikan Kolejinin binaları oldu ${ }^{42}$.

Türkiye, Avrupa ile Asya'yı birbirine bağlayan bir konumda yer alması ve dünyanın deģişik medeniyet ve kültürlerine ev sahipliği yapması, kısaca jeopolitik ve jeostratejik konumu nedeniyle yüzyıllardan beri pek çok tehditlere maruz kalmıştır. Bu tehditlerden en tehlikelisi eğitim alanında yürütülen misyoner faaliyetlerdir. Bu amaçla, Tanzimat ve Islahat Fermanları ile azınlıklara verilen haklar çerçevesinde Osmanlı toplumunda yaşayan Rum, Ermeni, Yahudi gibi azınlıklar, emperyalist Batılı devletlerin de desteğini alarak kendi dini inançları çerçevesinde Katolik, Ortodoks, Protestan okulları açmışlardır. İşte bu okullardan birisi de XIX. yüzyıl ortalarından itibaren Antep'te açılan ve merkezi Amerika Birleşik Devletleri'nde bulunan ABCFM tarafindan finansa edilen okullardır. Okulun en önemli amacı; Anadolu'nun Doğu ve Güneydoğu Anadolu Bölgesi'nde bulunan zeki Ermeni çocuklarını bu okullarda toplayıp, onları Ermeni

${ }^{38}$ Sarafian, Kevork A., A Briefer of History of Aintab. A Concise History of the Cultural, Religions, Educational, Political, Industrial and Commersial Life of the Amenians of Aintab, U.S.A. 1957. s.127-128.

${ }^{33}$ Sarafian, A.g.e., s.132.

4) Katchadourian, Stina, Efronia, An Armenian Love Story, Boston 1993. s.119-120; Sarafian, A.g.e., s.134; Riggs, Alice Shepard, Shepard of Aintab, New York 1920. s.191.

${ }^{41}$ Katchadourian, A.g.e., s.160.

${ }^{42}$ Yener, A.g.e., s.21. 
milliyetçiliği çerçevesinde Osmanlı Devleti aleyhine fikirlerle donatıp, Osmanlı Devleti karşıtı faaliyet gösterecek bireyler olarak yetiştirmektir. Açtıkları bu okullarda yürüttükleri çalışmalarla Osmanlı toplumundaki etnik ve dini bakımdan farklılıklar gösteren unsurların bağımsızlık hareketlerine zemin hazırlamışlardır. Bu bağlamda, 3 Mart 1924 yılında Mustafa Kemal Paşa'nın Tevhid-i Tedrisat Kanunu'nu çıkartarak Türkiye Cumhuriyeti sınırları içinde kalan yabancı okulları Milli Eğitim sistemi içine almıştır.

\section{KAYNAKÇA}

Aksoy, Ö. Asım, 80 Y $\boldsymbol{l}$ Ö Önceki Antep, Gaziantep Büyükşehir Bel. Kültür Dergisi (1992).

American Board of Commissioners for Foreign Missions, A Century of Service in the Fountain of Healing, HAK. PAMPH. Folio RA, 99 B, T8, Z 11.

Ayıntab'da Kain Merkezi Türkiye Koleji'nin 39. Senevi Raporu, Kolej Matb., Ayintab 1332.

Bilezikian, V. S., Abraham Hoja of Aintab, Light and Life Press, Winona Lake, Indiana.

Blake, Isabel M., Looking Backward Fifty Years in Aintab, Turkey.

Catalogue of Central Turkey College at Aintab 1880, Vilaye of Aleppo, 1881, Matteosian, Constantinople 1991.

Güzelbey, Cemil Cahit, Gaziantep Şeri Mahkeme Sicilleri, c.142, Gaziantep Kült. Der. Yay., Gaziantep 1966.

Katchadourian, Stina, Efronia, An Armenian Love Story, Boston 1993.

Kocabaş, Süleyman, Türkiye'de Gizli Tarih III, Misyonerlik ve Misyonerler, Vatan Yay., İstanbul 2002.

Mutlu, Şamil, Osmanlı Devleti'nde Misyoner Okulları, Gökkubbe Yay., İstanbul 2005.

Report of the President of Central Turkey College, Aintab, The Board of Manager of the College, 1913-1914. PUMPH Folio RA, 990, T8, Z 91.

Riggs, Alice Shepard, Shepard of Aintab, New York 1920.

Salname-i Nezaret-i Maarif-i Umumiye, Matbaa-i Amire, İstanbul 1317.

Salname-i Vilayet-i Haleb, Haleb Vilayeti Matbaası, Haleb 1285.

Salname-i Vilayet-i Haleb, Haleb Vilayeti Matb, Haleb 1310.

Salname-i Vilayet-i Haleb, Haleb Vilayeti Matb., Haleb 1326. 
Sarafian, Kevork A., A Briefer of History of Aintab. A Concise History of the Cultural, Religions, Educational, Political, Industrial and Commersial Life of the Amenians of Aintab, U.S.A. 1957.

Solmaz, M. - Yetkin H., Gaziantep Çevre Incelemesi, Yeni Matbaa, Gaziantep 1969.

Yener, Şakir Sabri, Gaziantep'in Yakın Tarihinden Notlar, Gazianteplilerin Maarife Hizmetleri. Gaziantep Vilayet Merkezinin 76 Sene Evveline Kadar Olan Mahalli Maarif Hareketlerinin Kısa Bir Tarihçesi, Gaziyurt Matb., Gaziantep 1955. 